\title{
LASER SCANNING OF A MONOLITHIC COLUMN DURING PROCESSING IN MIDDLE EGYPT
}

\author{
O.Ajioka ${ }^{\mathrm{a}, \mathrm{b}} *$ Y.Hori $^{\mathrm{a}}$ \\ ${ }^{\text {a }}$ Dep. of Architecture and Urban Design, Faculty of Human-Environment Studies, Kyushu University, 6-10-1, \\ Hakozaki, Higashi-ku, Fukuoka-shi, Fukuoka, Japan - hori@arch.kyushu-u.ac.jp \\ ${ }^{\mathrm{b}}$ Keisoku Research Consultant CO.,2-10-7, Yanaka, Adachi-ku, Tokyo, Japan - ajioka@krcnet.co.jp
}

KEY WORDS: Laser Scanning, Akoris, Monolithic column, Restoration of Processing, Quarry

\begin{abstract}
:
From ancient quarries around Akoris in Middle Egypt, which belong to the Ptolemaic and Roman periods, the stone blocks could be carried to the working area located in the outside of the city. Those blocks included a giant monolithic column measured approximately $14 \mathrm{~m}$ in length, which had been cracked for reasons unknown and must have contributed to disuse of monolith. The first deal is a comparison of plans drawn by the point clouds by laser scanning with those coming from plane-tabling, which had been one of popular methods for measuring in the last century. This part shows how the laser scanning technology is useful in far better measuring and documentation of the site. The second discuss is about a detailed assessment of the procedure of processing through the observation of chisel marks and the detail analysis about the 3 dimensional data. In the result, we are succeed to show the restoration of the procedure of the proceedings using guidelines and a wooden curve since we concentrate attention on the point of abstracting the centre line and shaving the surface into the round shape.
\end{abstract}

\section{INSTRUCTION}

One of our most valuable findings from quarries of Akoris area of the Middle Egypt in the Ptolemaic and Roman periods is that waste and blocks abandoned, which sometimes obstructed work and transport, were widely scattered over the platform and work area. Large mount of waste must have been emitted in the working area in the course of the extracting, processing, and transporting in the quarries, whence we can trace the changes that affected the productivity and engineering innovations occurred at the quarries or introduced from the outside of Egypt. There were plentiful supplies of identical limestone in and around the river Nile and the Mediterranean Sea, and in the Ptolemaic and Roman periods the local limestone was in fact already being used regularly in monuments or ordinary buildings.

We suggest that, in transporting and processing of stone blocks, various advanced techniques could be used whose picture for the moment is not yet as clear as that of the techniques applied for extracting and in the field of engineering, not of archaeology, the aim of specialists knowledge was to understand and reconstruct exactly the causes behind the effectiveness of mechanical instruments; for example, much attention has been paid to the lever, tackle and sledge, which made possible a method more productive of results (including less wasteful). In 1997 we found an abandoned stone column just outside of the city Akoris. It may be against such a background of cautious, practical conservatism that we have to envisage the whole history of the development of the ancient technology in quarries. Such slow, empirical advances are in the nature of things hard to document and they are the successes that survive, the failures that are swept away. Despite numerous indications of successful consideration of the variables of scale, movement, and materials by ancient engineers, notable failures such as the monolithic column stone demonstrate the knowledge of stone behaviour under processing, which was imagined by ancient masons in Akoris, was far from an exact science. As mentioned below, in regard to technique they were surely wrong to apply a method of processing to follows client's idea that a monolithic column more than $14 \mathrm{~m}$ long was achieved by supporting at three points.

In 2010, we carried out our investigation with a terrestrial laser scanner for three dimensional measuring and documenting the whole site. Akoris is located in middle Egypt at the $300 \mathrm{~km}$ south from Cairo and at the east side of Nile river. The city area of Akoris is $600 \mathrm{~m}$ in north and south, $300 \mathrm{~m}$ in east and west. The monolithic column (Fig.1) we deal in this thesis lied down in direction of east and west along the city wall constructed in the Last Pharaohs at the north-west of the site near the border with Tihna village. From ancient quarries around Akoris, which belong to the Ptolemaic and Roman periods, the stone blocks could be carried to the working area located in the outside of the city.

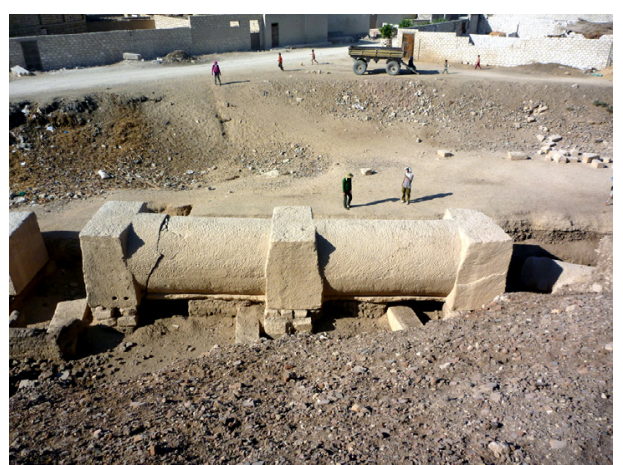

Figure 1. General view of the monolithic column

\footnotetext{
* Corresponding author. This is useful to know for communication with the appropriate person in cases with more than one author.
} 


\section{LASER SCANNING FOR THE MONOLITHIC COLUMN}

\subsection{The result of the laser scanning}

The laser scanner we applied in this investigation is 'ILRIS-3D' a product of Optech CO. To measure this column, we carried out laser scanning from 12 points not to occur occlusion (Fig.2). The 3 dimensional data of the column acquired by the laser scanner is consisted by 6million points (Fig.3).

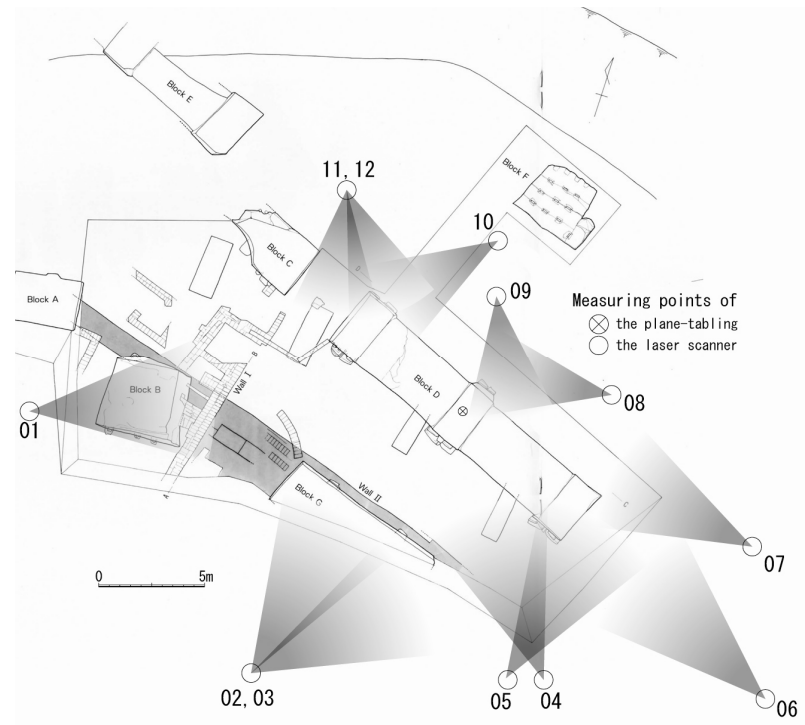

Figure 2. Measuring points of the laser scanner and the plane table

We created the laser orthographic images and drew the plan and four elevations by tracing those images (Fig.5).

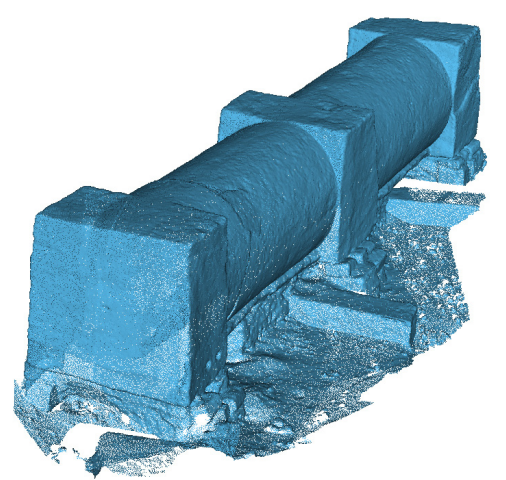

Figure 3. The result of the laser scanning

To check the degree of accuracy of the processing of the column, the detail comparison of the centre lines of the column has carried out by analysing the 3 dimensional data (Fig.4). Two lines those are the horizontal line through the small hole on the east side and the line connecting the centre points of each column sections are applied. The reason we have only applied the east sides is the west side had moved compulsorily by the crack. As the result, two lines are corresponded exactly in the plan and the horizontal line is $50 \mathrm{~mm}$ below another one in the elevation. The divergence between them is caused by reason that the column has been abandoned in progress. In the fact that the lower part of the cylindrical part is clearly in progress of the processing, we can mention that the processing of the column have been proceeded with high degree of accuracy excepting the unknown factor of the crack.

\subsection{Comparison with the results coming from plane table surveying}

The thorough excavation and investigation for and around this monolithic column have carried out three times by Kawanishi in 1997-1999. The result of them is published as 'PRELIMINARY REPORT AKORIS' in each year. Their archaeological survey is carried out using a plane-tabling and a level which were
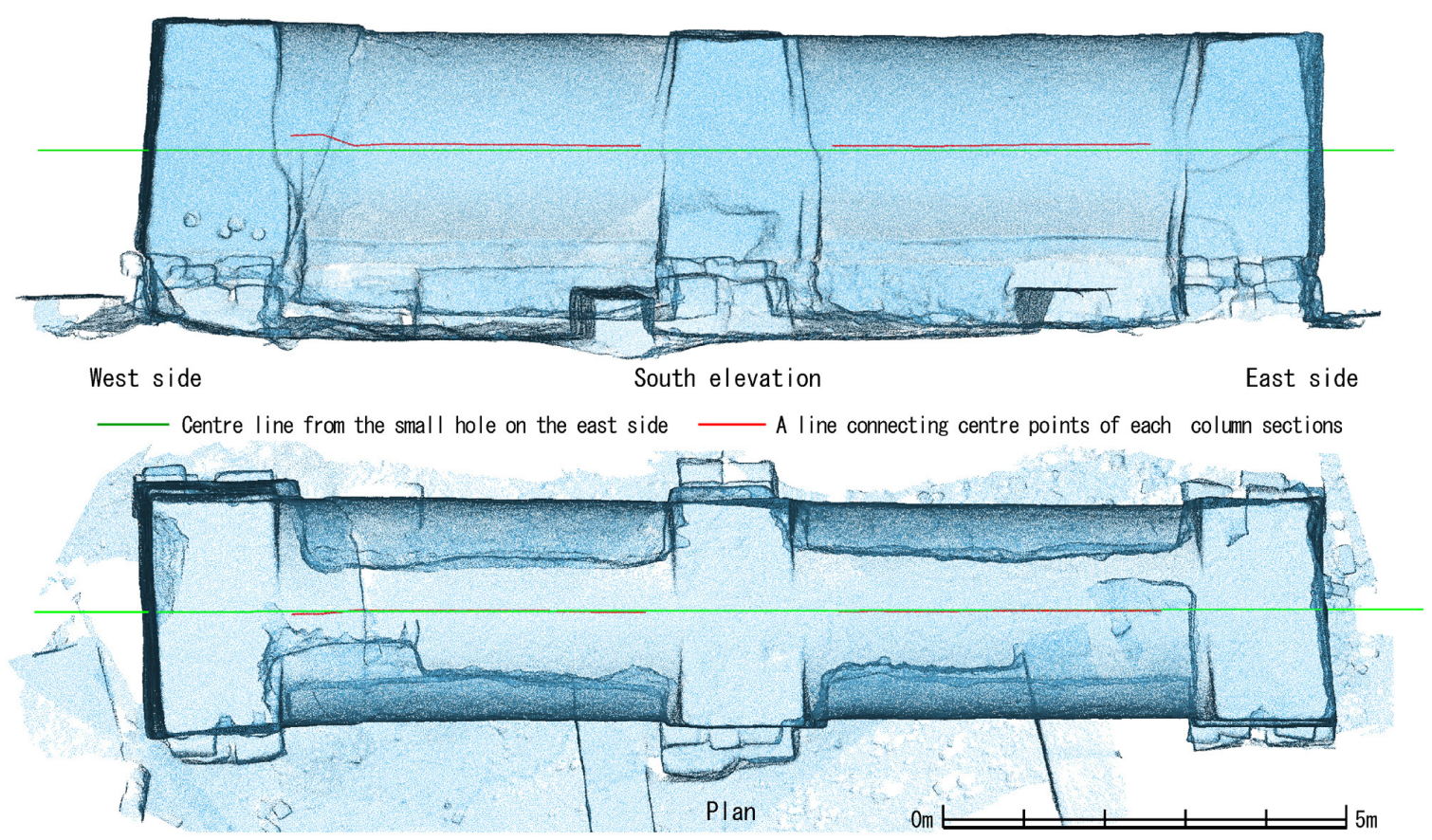

Figure 4. Comparison the centre line of the column with the line connecting centre points of each column sections 
popular methods for measuring in the last century. These methods are based on so simple measuring system that their results include a certain amount of errors necessarily. So, the drawings coming from plane-tabling and level has unavoidable errors despite the obvious care in their mensuration.

We tried to compare the plans drawn by the point clouds by laser scanning with those coming from plane-tabling and level. This part shows how the laser scanning technology is useful in far better measuring and documentation of the site. Between the plan by plane-tabling and level, and the results from scanning data, there is considerable divergence in the detailed shape of that block. It would have been difficult to maintain a high degree of accuracy in angulating on the waved and uneven surfaces of that giant block.

The next figure is the drawings layered the drawings coming from the point clouds with those coming from plane-tabling and level. We found out some divergence between them.

1. The shape of the plan is similar to a parallelogram. The two axis is not crossed vertically.

2. Comparing the elevations, the divergence of $150 \mathrm{~mm}$ is found in length.

3. The position of the crack running at western part is different about $500 \mathrm{~mm}$

Unavoidable errors included in the result of such old-fashioned methods are caused by some reason coming from its simple measuring system, human error and resolution of drawing lines. Especially, the measuring system is important. In use, a plane table is set over a position where can be seen from the objects to be measured. And to draw a line on the sheet with high degree of accuracy, the distance between the object and the position of plane table is needed to be measured accurately. The longer the distance, the more errors are increased. So, to carry out the survey efficiently and with high quality, the position a plane table is set is to be considered carefully. In our case, the measuring points where the laser scanner and plane table have set are showed in Figure.2. In measuring by the laser scanner, the distance from the laser scanner to the object is $27 \mathrm{~m}$ at its maximum. The raw range accuracy of the laser scanner we have applied is announced officially $7 \mathrm{~mm} @ 100 \mathrm{~m}$. In case of $27 \mathrm{~m}$, calculated error is about $\pm 3 \mathrm{~mm}$. Otherwise, the plane table is set at the centre of the stone block. The maximum distance is about $7.5 \mathrm{~m}$ which is not so long as much error includes in the result. The reason why the divergence occurs is considered that it is hard to measure the massive object such as the stone block. In general, plane-tabling is suitable for measuring the topography. That's why topography spreading flat is easy to be seen directly from the position the plane table was set. Certainly, the position the plane table was set is not so far from the object where the surveyors tried to measure. But the stone block has so a megalithic body that it is impossible to see the lower part of the stone block from the centre point of itself. Then the surveyors would use a plumb or a level staff to measure those invisible parts.

\section{RESTORATION OF THE PROCEDURE OF PROCESSING}

This monolithic column we found had a fate to be abandoned since any failure technique had operated for processing progress by ancient masons. If any trouble had not been caused, this monolithic column has been transported to the suburban port of Nile river after finishing the processing. Thanks to the failure, we have an opportunity to survey and understand in detail how the masons have processed such a megalithic and monolithic stone block into an ordered size of column with high degree of accuracy.

In the foregoing chapter, we introduced that we have acquired accurately 3 dimensional shape of this column by laser scanning
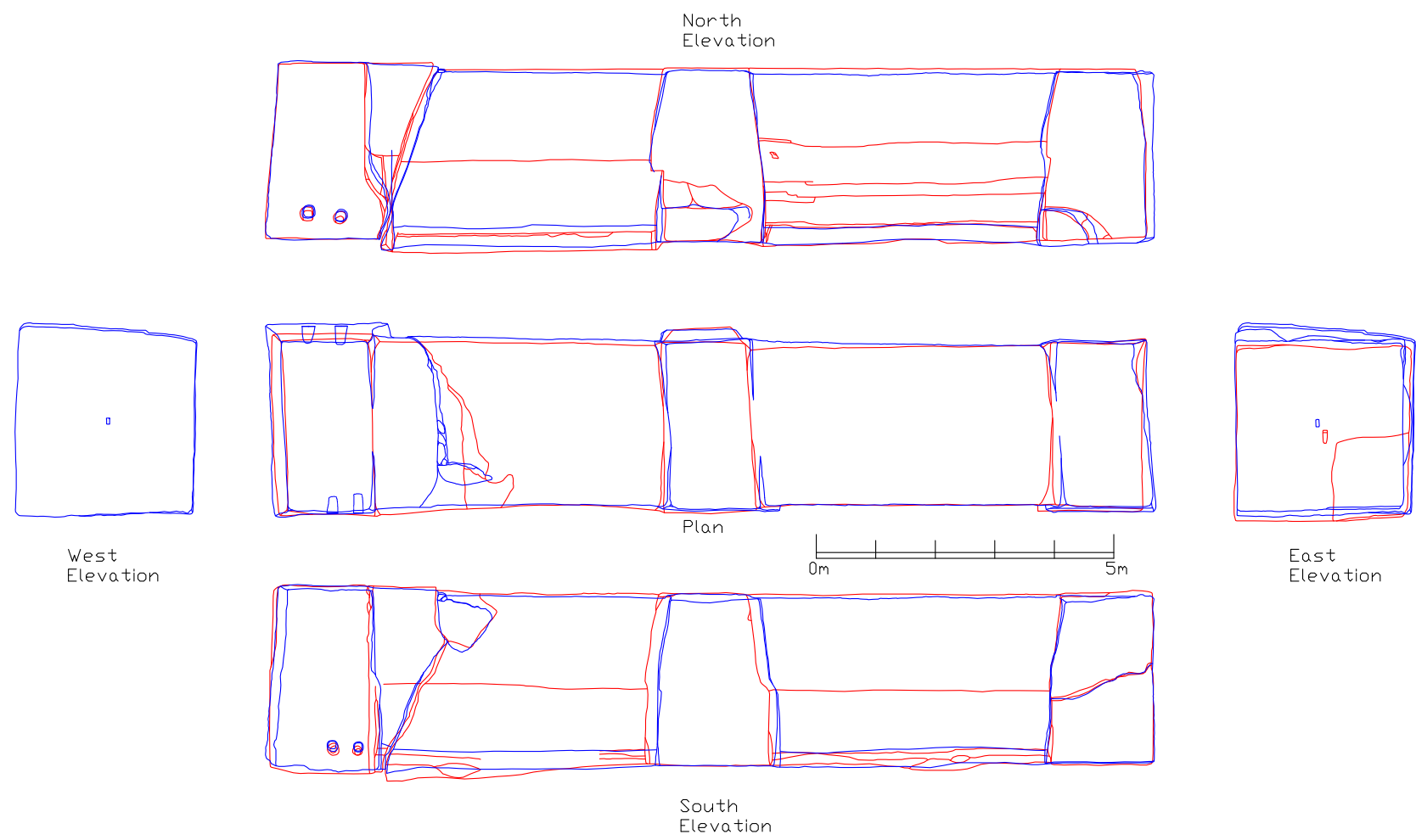

Figure 5. Comparison with the results coming from two methods

(Blue lines are the result of laser scanner. Red lines are the result of the table-tabling) 
and have created new drawings more accurate than those coming from the old-fashion methods. Moreover, new knowledge about the proceeding of this column is revealed by the analysis about our 3 dimensional data from multi points of view. In this chapter, we introduce a restoration model of the processing of the column by comparing with two types of evidence those are archaeological evidences such as chisel marks and the analysis coming from the 3 dimensional data of the column measuring by the leading-edge technology. In Ptolemaic and Roman periods that industry of extracting and processing stones from quarries has been prosperous, ancient masons must have constructed a technical know-how of processing. This column abandoned in progress of processing is the optimal material for us to understand their techniques.

For the purpose of restoration of the procedure of the processing, we have seek the ancient mason's processing by paying attention to the small hole creating the centre of the east and west side, chiselling marks and the sectional shape of this column. In the process of it, abstracting the centre of the column accurately and making the stone surface uniform round shape are considered the most difficult process from the technical point of view. To solve them, two methods are considered carefully those methods are the guidelines on the basis of the small hole and using a wooden curve. In the result as the inspection of the short sections of the column, it is clear that the western square part is the biggest part after the careful thought of the gap caused by the crack (Fig.8). Therefore, we can mention that the stone block has been a rectangular parallelepiped shape at that point the stone block had transported to this work area from the quarry. The process we considered is below (Fig.10):

1. Make a small hole on the both side of the stone block.

2. Set a crossed arm at the centre of the small hole. And both sides of arms are connected by ropes as guidelines.

3. Excepting the square part supported by base stones, shave of the stone surface into a polygonal shape depending on the guideline

4. Hold the wooden curve which has same radius of the ordered size to the surface of the stone. Then shave off the unfit point.

5. After that, repeat the same work until the curve would fit to the surface.

It is the general method to make a small hole at the centre of the side of the stone and deciding the position of the centre line. It is the important step for keeping the degree of accuracy to abstract the centre line accurately Fig.7). We can explain the existence of the guideline from the border line of the chisel marks on the north and south sides. The border lines found at the 4 places is drawing lines between the upper and lower chisel marks and they runs horizontally (Fig.7, 9). Even more, 3 lines excepting a line on the north side east is founded same height. On the north side east, the border lines between chisel marks are founded 2 lines, and the middle of them is the same height with the other 3 lines. As mentioned above, it is considered that any guideline would be existed. The divergence between the centre line and the border lines is $100-200 \mathrm{~mm}$. The reason it is occurred can mentioned that the masons have been worked their work avoiding the ropes. If the guidelines have been set enough separately from the column, the accuracy as the guidelines would not have been kept.
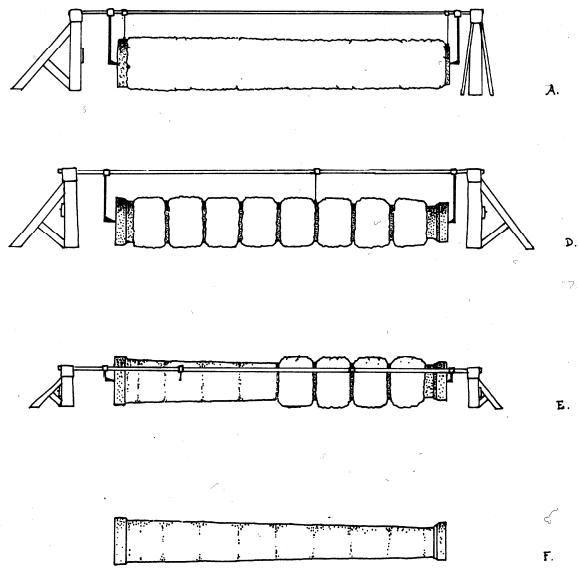

Figure 7. A type of the procedure of processing of a column

Observing the sectional shape and the chisel marks gives us the understanding about the process to shave off the stone block into a polygonal section we explained in 3. The lower part of the cylindrical part is shaven in straight lines by a pointed chisel (Fig.9). It is considered that this technique is to shave the surface of the stone into a plane surface. On the north side east, we can found a plane surface. If it has been regarded as the part of making slow progress, we could consider that this surface would be a remaining of a polygonal surface.

It is guessed that the method using the wooden curve has been used since the ancient Greek period. In the case of shaving a polygonal surface into a round shape, the wooden curve must hold into the surface vertically. To hold it vertical accurately, the guideline is used. Attaching a scale to the guideline makes it possible to the curve to hold into the surface vertically with suiting the same scale from the edge.

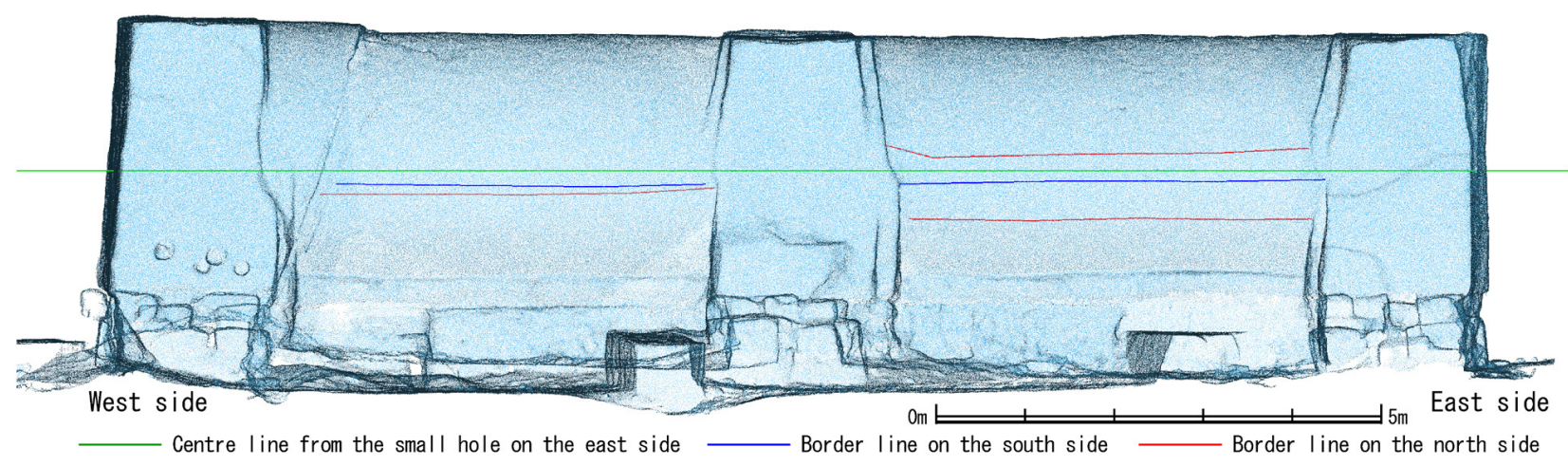

Figure 6. Comparison the centre line of the column with the border line of the chisel marks on the north and south side 


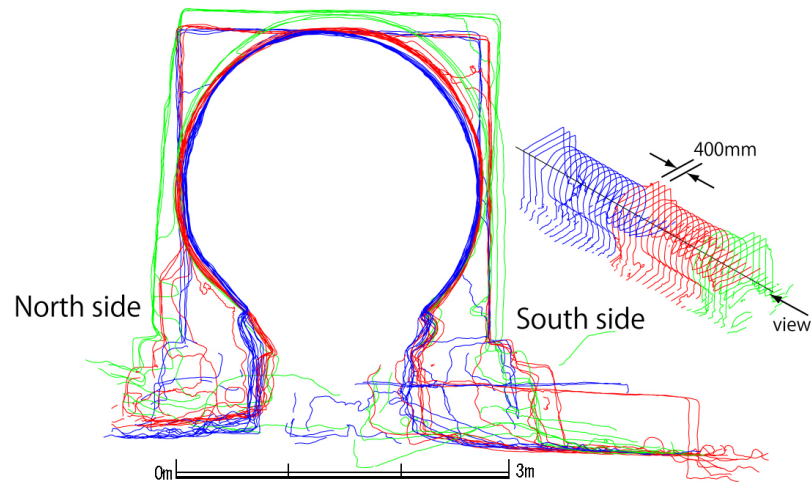

Figure 8. North-south continuance sections of the column

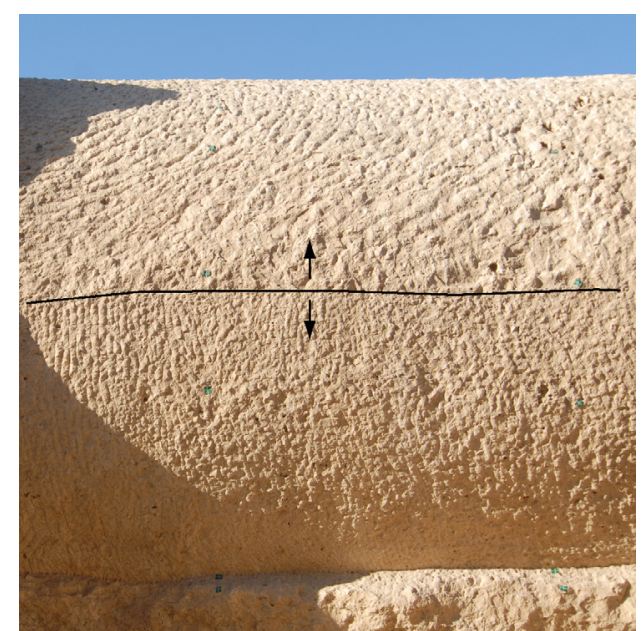

Figure9. The border line of chisel marks on the south side

Holding the curve into the surface, if it would not fit, the curve has been moved horizontally and shaving operation has done. And hold it once again, if there would not any projection, the processing has advanced next stage. To shave lower part of the cylindrical part, the curve is not moved horizontally but rotated along the surface of the cylinder. We consider that it is possible to produce the ordered sized column using the methods as mentioned above. In the analysing the 3 dimensional data, we found out interesting fact in related to the procedure of the processing which could not become a topic in this thesis. For example, the inclination of the squarer part of the north and south side is almost parallel. It must be related to the processing. Moreover the reason of occurring the crack which is the biggest mystery of this column will be solved by analysing 3 dimensional data and observing the archaeological evidences much more.

\section{CONCLUSION}

Ptolemaic architecture, for reasons that it had been deeply and clearly affected by ancient Egyptian, embraced the practice of erecting monolithic column shafts in addition to more traditional fluted drum shafts in Greek mainland. Though it would have been too difficult to lift, transport, and elect a colossus or obelisk out of its quarry hole, the Egyptian engineer opened the front of the hole as well so that the block could be levered or pushed out more easily and rolled down over its long side to the transport ramp. Both in their production of megalithic and monolithic stone blocks and in their approach to the problems of transportation the Ptolemaic engineers seem to have learned heavily upon proceeding Pharaonic experience,
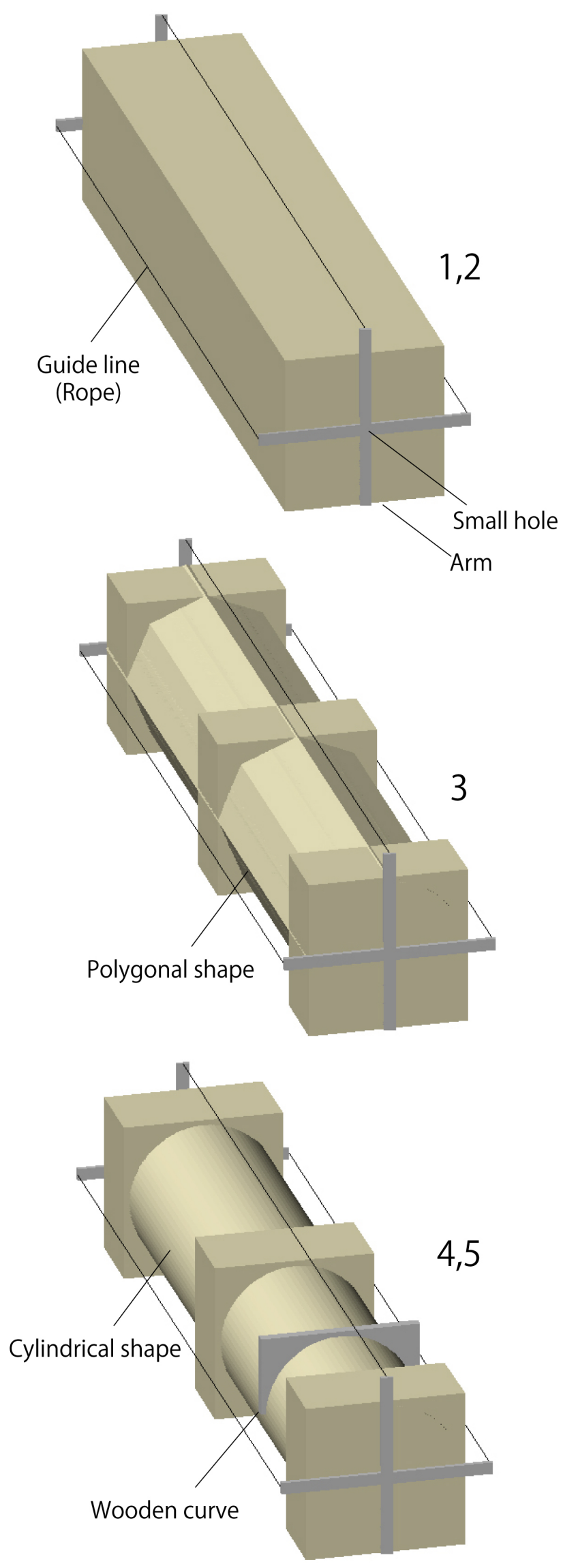

Fig.10 The restoration model of the procedure of the processing 
freely interpreted in terms of local materials, transporting skills, and traditions. However they failed to complete their work.

With its fusion of Greek and Pharaonic traditions, one of unique characteristics of Ptolemaic Egypt is the particular form of the megalithic character which it was devoted; and since one cannot imagine that so precisely articulated and monumental that block was extracted for a building of a modest provincial city in the middle Egypt, there can be little doubt that it reflects unknown construction project in the capital, Alexandria or other majour cities. As coloured marble, porphyry, and granite was imported from quarries around the empire, Roman builders suppressed the Greek tradition of creating columns from stacked cylindrical drums of white marble and easily adopted new column styles with solid monolithic shafts in exotic imported stone. The rich country of Egypt, with the considerable stone resources, fell into the hands of a quite new kind of people, might provide with an almost unparalleled technical genius and energy in opposing such monolithic tradition in Egypt and segmental in Greece. The same can be said of the Ptolemaic people, whatever their origin was, and in spite of what they learned from the Egyptians.

That monolithic column block that we found, ordered in the late Ptolemaic period and whose length is reached up to $14 \mathrm{~m}$, was, however, cracked just before the finishing. Instead of succumbing simply to fate, then, that monolithic block appears to have been a victim of their megalithic and monolithic tradition on Egypt, which proved fatal to its long, unproductive structure. Easily interpreted as a Gothic Babel Tower doomed to failure by its audacity, a more simplistic view of that monolithic column in the Ptolemaic period and its place in the development reveals much about the whole process of quarrying in the Ptolemaic period and demonstrates the importance of productive and technical factors in the large architectural projects. It is interesting in this context to remember that that important technique in the development of the monolithic and megalithic architecture had no obvious direct successors in Rome until the Colosseum and the Pantheon, I suspect, because they were considered failures technically under the Greek tradition.

\section{REFERENCE}

H. Kawanishi, 1997-1999, PRELIMINARY REPORT AKORIS, History and Anthropology University of Tsukuba

G. Ponti, 2006, Techniche di estrazione e di lavorazione delle colonne monolitiche di granito Troadense, in "i marmi colorati della Roma imp[eriale", Verona

Jean-Claude BESSAC, 1993, l'outillage traditionnel du tailleur de pierre del'Antiquité à nos jours, Paris, Fig. 58, Fig. 60

\section{ACKNOWLEGEMENT}

The fieldwork was financed by the Grant-in Aid for Scientific Research, the Ministry of Education, Science and Culture, Japan. Thanks are due to Dr. Zahi HAWAS, Minister of Antiquities, who granted the team permission to work at Akoris, to Prof. Hiroyuki KAWANISHI in Tsukuba University and Dr. Sumiyo TSUJIMURA in Kokushikan University, the Director and Supervisors of the survey. We are grateful to Cairo branch of KAJIMA Corp., which provided support needed to carry out this survey and engineers in KEISOKU RESEARCH CONSULTANT Corp. in Japan, who lent their cheerful collaboration to the task and offered many useful technological comments. This paper is a part of the result of research projects, "Development of Stone buildings and the Treatment of the Stone as a building material ", (director Prof. Yoshiki HORI in Kyushu University) and "The political geography of peninsular Italy in the ancient Roman period", (director Prof. Koji TOYOATA in Sophia University) which are financed by J.S.P.S. (Japan Society of Promotion of Science). 